\title{
A Cadeia produtiva do tabaco na região Sul do Brasil: aspectos quantitativos e qualitativos
}

Éder Jardel Dutra*

Roni Hilsinger**
Resumo: A partir de referenciais como Delgado (1985), Etges (1991), aborda-se a produção fumageira em seus aspectos quantitativos e qualitativos nos estados do Rio Grande do Sul, Santa Catarina e Paraná. Com a utilização da abordagem qualitativa, procura-se identificar as consequências para a cadeia produtiva a partir da adoção das políticas restritivas, geradas pela adesão do Brasil as normativas da Convenção Quadro, política setorial que visa restringir o cultivo do tabaco. Destacam-se os interesses que envolvem a fumicultura, representados pelos defensores da atividade e por setores contrários à produção fumageira, evidenciando as distintas concepções que envolvem a discussão.

\section{The production chain of tobacco in Southern Brazil: quantitative and qualitative aspects}

\footnotetext{
Abstract: From references as Delgado (1985) and Etges (1991), it is addressed the tobacco production in its quantitative and qualitative aspects in the states of Rio Grande do Sul, Santa Catarina and Paraná. With the use of a qualitative approach, we seek to identify the consequences for the productive chain from the adoption of restrictive policies, generated by the adhesion of Brazil to the Framework Convention normatives, sectoral policy that aims at restricting tobacco cultivation. Noteworthy are the interests that involve tobacco farming, represented by advocates of the activity and by sectors against the tobacco production, demonstrating the distinct conceptions involving the discussion.
}

* Doutorando em Geografia pelo PPG da Universidade Federal do Rio Grande do Sul (UFRGS). Bolsista CAPES

** Doutorando em Geografia pelo PPG da UFRGS.
Palavras-chave: Cadeia produtiva; Produção de fumo; Região Sul do Brasil

Key-Words: Productive chain; Tobacco production; Southern Brazil 


\section{Introdução}

A fumicultura é uma atividade econômica que se desenvolveu primeiro no nordeste do Brasil, todavia, também em outras áreas do território nacional. Sobretudo, ao longo do século XX concentrada nos estados do Sul do Brasil (Rio Grande do Sul, Santa Catarina e Paraná). Envolvendo ampla gama de municípios, consolidou sua importância econômica como uma cadeia produtiva que gera empregos inclusive em áreas rurais.

Nos últimos 20 anos tem se desenvolvido, principalmente na região Sul do Brasil, fundamentalmente no estado do Rio Grande do Sul, com acentuada concentração do cultivo e plantas industriais para beneficiamento e exportação. É importante destacar, que a evolução da fumicultura conserva algumas características, que a tornam peculiar, especialmente por utilizar estruturas de propriedades familiares na produção.

Com a expansão dos complexos agroindustriais, fundamentalmente ao longo dos anos 80 do século XX, a fumicultura passa a ter o predomínio do capital internacional, como um dos reflexos da modernização agrícola. Com a intensificação das relações capitalistas, muitas famílias de agricultores que enfrentavam dificuldades, aderem ao plantio de fumo como uma das formas de sobrevivência.

Por ser uma atividade polemica, a fumicultura envolve uma serie de elementos conflitantes, entre os defensores da atividade estão às entidades de classe que utilizam fundamentalmente dados econômicos, como numero de famílias envolvidas, geração de impostos, entre outros. De outro lado, estão os antibagistas, vinculados em especial aos órgãos promotores da saúde publica. $\mathrm{O}$ assunto é polemico assim, o presente ensaio teórico pretende discutir a atividade e destacar as diferentes concepções que estão envolvidas na discussão, principalmente as restrições impostas pela Convenção Quadro de controle e consumo dos produtos oriundos do tabaco.

O artigo é composto pelas seguintes partes: Introdução, Metodologia, A fumicultura no Brasil, A modernização no campo e a agricultura familiar, Perspectivas da fumicultura no Brasil e Considerações finais.

$\mathrm{Na}$ Introdução descrevem-se a importância da fumicultura e a forma como os agricultores familiares aderem à fumicultura. Na Metodologia é feita a descrição do método de pesquisa e o tipo de abordagem que evidencia os atores envolvidos com a produção fumageira. Em 'A fumicultura no Brasil' é feito breve levantamento das origens do fumo no mundo e, sobretudo, no Brasil e posterior disseminação do consumo. Em 'A modernização no campo e a agricultura familiar' destacam-se as inter-relações entre os processos modernizantes e seus desdobramentos no universo da agricultura familiar, em especial com a integração à indústria.

O capitulo 'As perspectivas da fumicultura no Brasil' destaca a expansão do complexo agrofumageiro via sistema integrado de produção e as problemáticas advindas com a adesão do Brasil à Convenção Quadro, principalmente com as restrições ao plantio e ao consumo.

\section{Metodologia}

Geografia Ensino \& Pesquisa, v. 17, n.3 p. 17-33, set./dez. 2013

A Cadeia Produtiva do tabaco na região Sul do Brasil: aspectos quantitativos e qualitativos
A pesquisa requer um objeto e exige a delimitação espacial do mesmo. Tal demarcação da área pesquisada pretende seguir o critério de importância socioeconômica da fumicultura no setor familiar em municípios gaúchos, catarinenses e paranaenses. Segundo Raffestin et al. (1983, p.124) "não se pode aceitar [...] que uma pesquisa seja conduzida sem que a escala esteja claramente especificada".

Partindo desse pressuposto, admite-se a necessidade de utilizar diferentes escalas, 
conforme o raio de ação de cada ator. Ao discutir-se a erradicação do cultivo de fumo no Brasil e no mundo parte-se, por exemplo, de uma decisão tomada em escala global representada pela Organização das Nações Unidas (ONU) por meio da Organização Mundial da Saúde (OMS).

Como serão analisados os reflexos de políticas definidas por organismos internacionais e nacionais (é o caso da ratificação brasileira à Convenção Quadro), não se podem ignorar as relações que estes mantêm com a escala global, uma vez que a autonomia do local é condicionada e influenciada por aspectos que lhe são externos. O local não se explica em si, mas a partir das relações que são mantidas com o todo. "O domínio das escalas é, portanto, um elemento prévio a toda a ação". (RAFFESTIN et al. 1983, p.134).

Conforme destaca a Fig. 1, a fumicultura é uma atividade que envolve as esferas de atuação de distintos atores. Isso não exclui a sobreposição de esferas de atuação dos atores e suas intencionalidades, em razão das especificidades que envolvem a atividade.

Figura 1 - Atores envolvidos na fumicultura e suas escalas de poder

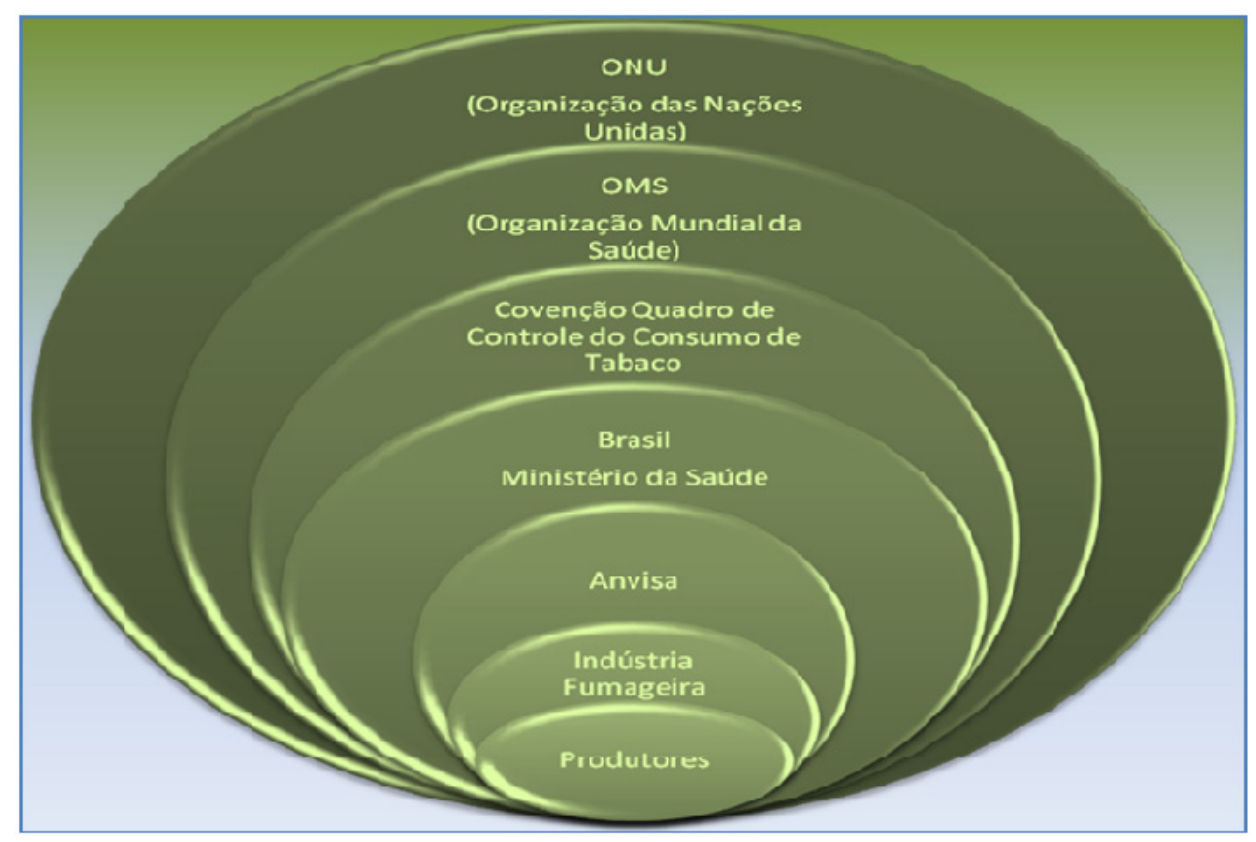

Fonte: Elaborado pelos autores, 2012.

A área de estudo compreende a produção de tabaco nos estados do Rio Grande do Sul, Santa Catarina e Paraná. Foram utilizados dados de campo obtidos de fontes primárias (orientadores agrícolas e produtores), mas também dados secundários, de entidades de classe como a Associação dos Fumicultores do Brasil (AFUBRA), o Sindicato das Indústrias do Tabaco (SindiTabaco) e o Departamento de Estudos Socioeconômicos Rurais (Deser) que visam a subsidiar a realização da pesquisa.

É importante destacar que o presente trabalho utiliza abordagem qualitativa. Assim:

A abordagem qualitativa parte do fundamento de que há uma relação dinâmica entre o mundo real e o sujeito, uma interdependência entre sujeito e o objeto, um vinculo indissociável entre o mundo subjetivo e a subjetividade do sujeito. (CHIZZOTTI, 1995, p. 79)

Geografia Ensino \& Pesquisa, v. 17, n. 3 p. $17-33$, set./dez. 2013

É preciso entrever:

A existência de pesquisas qualitativas onde não se descarta a coleta de dados quantitativos, principalmente na etapa exploratória de um campo, 
ou nas etapas em que estes dados podem mostrar uma relação entre fenômenos particulares. (CHIZZOTTI, 1995, p. 84)

Foram sistematizados esquemas representativos que evidenciam a importância que a fumicultura adquiriu no sul do Brasil. A fotografia utilizada foi obtida por meio de visitas de campo realizada pelos autores, nas propriedades fumicultoras, selecionando-se aquela que sintetiza as peculiaridades da produção na escala analisada.

\section{A fumicultura no Brasil}

O fumo ${ }^{1}$ é uma cultura agrícola que, no sul do Brasil, é cultivada em estruturas fundiárias de propriedades familiares, com emprego intensivo de mão-de-obra. A cultura do tabaco já estava presente na agricultura colonial, mas até o inicio do século XX era pouco expressiva em quesitos como área plantada e volumes de produção.

1- O fumo ou tabaco são designações vulgares de diversas plantas do gênero Nicotiana (família das Solanáceas) particularmente a Nicotiana Tabacum e a Nicotiana Rústica e dos produtos que são elaborados com suas folhas. (ETGES, 1991, p, 39)
Geografia Ensino \& Pesquisa, v. 17, n.3 p. $17-33$, set./dez. 2013

A Cadeia Produtiva do tabaco na região Sul do Brasil: aspectos quantitativos e qualitativos
Etges (1991) com base em Sangirardi Jr. (1983), diz:

Os historiadores que trataram a temática da ocupação e colonização do Brasil salientam que a origem do nome tabaco está atrelada a uma pequena ilha do Caribe de nome Tobago. Cristovão Colombo chegou a Tobago em 1498 e seis anos antes ao atual Haiti, encontrando a palavra entre os índios Arawak. Outros destacam que o tabaco já era conhecido na Ásia desde o século IX, tendo origem na palavra árabe 'tabbâq', que designava determinadas plantas fumadas em cachimbo. (ETGES, 1991, p. 40)

Em que pese às diversas teorias e divergências sobre a origem do fumo, é preciso ter em conta o que destaca Etges (1991) com base na obra A História do Fumo Brasileiro de Jean Batisti Nardi (1985), quando afirma que:

O local provável para o surgimento do fumo tenha sido os vales orientais dos Andes Bolivianos e dali tenha se difundido através do território brasileiro pelas migrações indígenas, sobretudo Tupy-Guarani. Quando da chegada dos europeus, o fumo era de uso comum nas tribos indígenas e cultivado em toda a costa brasileira. Depois da chegada do navegador genovês a serviço da coroa espanhola, Cristovão Colombo, o fumo passou a ser conhecido em vários lugares. (ETGES, 1991, p. 41)

Com relação ao cultivo do fumo no Brasil é necessário recorrer a Etges, quando diz que:

Durante os três primeiros quartos do século XVI, os colonos portugueses obtiveram o fumo dos índios através de um sistema de trocas, entretanto, com os inúmeros confrontos entre índios e portugueses, os colonizadores passaram a cultivá-lo, tendo em vista o florescente comércio. (ETGES, 1991, p. 43)

A maioria das culturas agrícolas cultivadas no Brasil (soja, cana-de-açúcar e algodão) tem por objetivo principal atender o mercado externo e, por sua vez, utilizam grandes extensões de terra. A produção de fumo, embora tenha por objetivo atender as necessidades do mercado externo, era cultivado "em pequenas propriedades na faixa litorânea, fundamentalmente no espaço compreendido entre Salvador e Recife, sobretudo nos arredores de Cachoeira, no Recôncavo Baiano, onde surgiram as primeiras roças”. (ETGES, 1991, p. 43)

Em razão do mercado interno não absorver a produção, o fumo produzido era direcionado na maior parte à exportação. Naquele momento, a exportação possuía destinos diferenciados, sobretudo a Europa, como reflexo das relações comerciais à época. 
O fumo exportado tinha três destinos principais, a saber: (i) o de primeira qualidade era mandado para Lisboa e redirecionado para outros países; (ii) os de qualidade inferior eram mandados para a Índia; (iii) a partir do final do século XVIII, passou a ser exportado também para o Uruguai e Argentina (ETGES, 1991, p. 44).

A política de incentivos do governo nos primeiros anos do século XX possibilitou a desconcentração espacial do cultivo, com o surgimento da produção em estados como Goiás e Minas Gerais. Mas foi, sobretudo no Rio Grande do Sul que, em decorrência da ampla disponibilidade de mão-de-obra, houve a expansão da área cultivada, com destaque para o atual município de Santa Cruz do Sul, onde naquele momento já existia expressiva colônia alemã.

Fruto da necessidade de aumento da produção e do florescente comércio, em muitos casos os próprios colonos recorreram a cruzamentos de variedades de fumo. Mas à época dois eram os tipos predominantes: (i) fumos escuros e (ii) fumos claros. Todavia, os fumos escuros ficaram restritos a cultivos no nordeste do Brasil, especialmente para confecção de charutos, enquanto os fumos claros:

\begin{abstract}
Deram resultado efetivo no estado do Rio Grande do Sul, importados de Cuba e dos Estados Unidos da América. Em 1870 foi introduzido o tipo ‘chinês' do qual se originou o 'amarelinho' que passou a ser cultivado em larga escala na província. O tipo 'Virginia' foi introduzido em 1920 e rapidamente, por suas vantagens em termos de rendimento, facilidade na secagem e boa qualidade apresentada, transformou-se numa das variedades bastante cultivada no Brasil. (ETGES, 1991, p. 46).
\end{abstract}

Entre os fatores que permitiram a ampliação da cultura do fumo no Rio Grande do Sul está a disponibilidade de mão-de-obra nas colônias de origem alemã, permitindo a consolidação do estado como um dos principais produtores. É preciso destacar que gradualmente muitas empresas passaram a transferir ou implantar novas indústrias, possibilitando assim, dinamismo ao setor com absorção da produção oriunda das propriedades familiares.

Já no final dos anos de 1970 e inicio dos anos 1980 o processo de modernização implicou alterações na estrutura agrária. A implantação dos complexos agroindustriais (CAIs) possibilitou a expansão do cultivo de fumo nos pós-década de 80 impondo nova lógica aos processos produtivos e por consequência intensificando as relações de produção.

Essa expansão deu-se fundamentalmente pelo suporte fornecido e pelas relações estabelecidas a partir da existência e consolidação do sistema integrado de produção. É necessário salientar que "a integração, nascida da forma empresarial, busca seu desenvolvimento em regiões de forte presença do que hoje chamamos de agricultura familiar". (ALVES et.al, 2005, p .153)

O processo de implantação dos complexos agroindustriais e sua operacionalização via sistema integrado de produção é um reflexo dos processos de modernização que passaram a predominar no Brasil. Esse conjunto de alterações nas características da agricultura brasileira consolida-se especialmente após a década de 70, mas intensifica-se ao longo dos anos 80, possibilitando a inserção econômica de setores da agricultura familiar.

\title{
A modernização no campo e a agricultura familiar
}

O estudo do espaço agrário durante o século XX, em especial da agricultura familiar, exige compreender a evolução da economia e do Estado brasileiro, visto que a agricultura é um importante setor da economia nacional e o Estado o principal ator que formula e executa

Geografia Ensino \& Pesquisa, v. 17, n. 3 p. $17-33$, set./dez. 2013

Dutra, E.J.; Hilsinger, R. 
as políticas públicas.

O Estado brasileiro passou por transformações a partir da década de 1980. O seu papel desenvolvimentista de Estado-empresa, inspirado nos preceitos da Comissão Econômica para a América Latina e o Caribe (CEPAL), passou a enfrentar dificuldades financeiras e políticas para seguir o projeto territorial nacional. O colapso do socialismo, a ascensão de múltiplos polos hegemônicos mundiais e as crises do petróleo são fatores que lançaram grandes incertezas no plano mundial. As pressões políticas para a redemocratização e a convocação da Constituinte que elaborou a Constituição de 1988 são direcionamentos que puseram em dúvida o modelo de Estado que vigorava.

Até aquele momento o Estado era o único vetor de poder. O território brasileiro era a base geográfica onde ele exercia o poder, mediante as políticas territoriais e setoriais. O que ocorre com o Estado brasileiro é pontual:

Conflitos entre forças internacionais e nacionais, entre grupos sociais que compõem a formação social e entre segmentos do próprio Estado ressaltam a importância da instância política e demonstram que o aparelho governamental não é mais o instrumento único de poder (BECKER, 1986, p.6).

As principais mudanças são: o surgimento de múltiplos vetores de poder; a multidimensionalidade do poder; os diversos atores atuam relacionados com o Estado; o ressurgimento do território não apenas como espaço próprio do Estado-nação, mas sim dos diferentes atores sociais, a manifestação do poder dos atores sobre uma área precisa (BECKER, 1986, p. 6).

A inserção brasileira na economia mundial mediante o processo da globalização foi acelerada pela adoção de políticas liberais em resposta à crise fiscal do Estado desenvolvimentista. O seguimento às doutrinas de organismos internacionais, fundamentadas em políticas econômicas - que tinham como palavras-chave a) estabilizar, b) desregular e c) privatizar - levaram ao mundo capitalista a mensagem de que o mercado era o único mecanismo competente de auto-regulação econômica e social. O Brasil no seu processo de transição:

Para um Estado democrático e descentralizado adotou as políticas liberais como resposta à crise fiscal do Estado desenvolvimentista. Com isso, perdeu o controle sobre as flutuações monetárias e os fluxos financeiros. Generalizou-se a convicção liberal de que, junto com a inviabilização das economias capitalistas autárquicas e a universalização dos mercados, também se esgotara a função econômica dos Estados nacionais (FIORI, 1994, p.299).

Geografia Ensino \& Pesquisa, v. 17, n.3 p. 17-33, set./dez. 2013

A Cadeia Produtiva do tabaco na região Sul do Brasil: aspectos quantitativos $\mathrm{e}$ qualitativos
Essas são as condições sobre as quais se deu a formulação de políticas públicas pósdemocratização. O Brasil encontrava-se inserido numa posição periférica na economia global e enfrentava uma grave crise fiscal. O país tinha forte dependência externa e por isso se adequou às diretrizes de organismos internacionais.

Esses fatores enfraqueceram o planejamento e ação desenvolvimentista do Estado. Além disso, houve surgimento de atores sociais que passaram a atuar como parceiros, fazendo valer as suas aspirações e objetivos. Pode-se apontar a presença dos grupos transnacionais na economia brasileira, dos movimentos sociais, da agricultura familiar, dos estados e municípios que passaram a ser protagonistas.

Os grupos empresariais transnacionais, atores econômicos com origens e atuações múltiplas, sem apego territorial ou nacionalista, interessados em ocupar espaços, se encarregam, por seus objetivos (indústria, comércio, produção e serviços), de propiciar condições para que grupos sociais marginalizados e/ou excluídos das políticas públicas (como exemplo, a agricultura familiar) passem a ter protagonismo atendendo aos interesses de mercado. 
Nesse contexto surgem as condições para a consolidação dos complexos agroindustriais.

Os complexos agroindustriais foram formados a partir da introdução da lógica capitalista no campo, capaz de transformar a produção em agronegócio (industrialização da agricultura), sendo incorporados ao processo produtivo, tratores, colheitadeiras, produtos químicos e sementes selecionadas, cuja produção foi orientada para uma demanda de origem urbana e industrial (MARAFON, 2009, p. 333).

A produção agrícola que visa a atender o mercado externo e tem suporte nos complexos agroindustriais, ampliou-se e as linhas de credito cumpriram importante papel ao dar suporte ao processo em desenvolvimento.

O surgimento e consolidação do complexo agroindustrial articula interesses sociais comprometidos com o processo de modernização. Conforma um novo bloco de interesses rurais em que sobressai a participação do grande capital industrial, do Estado e dos grandes e médios proprietários rurais (DELGADO, 1985, p. 41).

Dessa forma, a modernização do campo:

Realiza-se com intensa diferenciação e mesmo exclusão de grupos sociais e regiões econômicas. Não é, portanto, um processo que homogeneíza o espaço econômico e tampouco o espectro social e tecnológico da agricultura brasileira (DELGADO, 1985, p.42).

A modernização no campo ao articular os interesses do capital permitiu que houvesse disparidades entre setores, permitindo e ampliando as desigualdades que já imperavam no meio rural.

Dentro dos padrões de modernização do campo alguns setores inserem-se em uma lógica capitalista e a agricultura familiar em parte adere ao processo, especialmente aqueles produtores que tem ligação com os complexos agroindustriais.

A inserção da agricultura familiar na lógica capitalista é um processo lento que perpassa por diferentes etapas, todavia consolida-se sobremaneira após os anos 1980, período em que a estrutura familiar de produção passa a ser utilizada como elemento, visando dar vazão às necessidades do processo de modernização no campo.

Um dos exemplos significativos é o dos agricultores que por falta de alternativas em outras produções (leite, conservas e frangos,...) ingressam na fumicultura, produção essa destinada aos mercados externos, articulando a lógica de conexão do local ao global em que a agricultura familiar é um dos elementos que compõem essa dinâmica. A fumicultura, que tem por objetivo atender às necessidades do mercado externo e que desenvolve-se sob a lógica em que articulam-se diferentes escalas de poder, é um exemplo significativo do novo momento ao qual está submetida a agricultura brasileira.

Ao enfocarem-se os aspectos quantitativos da fumicultura, percebe-se a dinâmica que envolve a atividade, articulando diferentes escalas e esferas de influencia (local, regional e global). Os números evidenciam as transformações da agricultura brasileira e as implicações do processo de modernização, caracterizando uma nova realidade, em pleno desenvolvimento.

A Tabela 1 faz referência aos países exportadores de fumo, Estados Unidos da América, Zimbábue e Brasil. Os dois primeiros países que foram significativos na exportação, até o inicio dos anos 1990, perdem posições no mercado internacional, todavia é preciso salientar que, ao longo dos anos 1990, por uma série de razões o Brasil passa a liderar as exportações em nível mundial.

Geografia Ensino \& Pesquisa, v. 17, n.3 p. $17-33$, set./dez. 2013

Dutra, E.J.; Hilsinger, R. 
Tabela 1 - Principais países exportadores de fumo

\begin{tabular}{lccc}
\hline Ano & Brasil $(t)$ & Estados Unidos $(t)$ & Zimbábue $(t)$ \\
\hline 1980 & 129.900 & 273.480 & 98.980 \\
1990 & 198.040 & 223.410 & 122.350 \\
2000 & 353.020 & 179.890 & 182.070 \\
2001 & 443.900 & 186.300 & 135.020 \\
2002 & 474.470 & 153.320 & 142.810 \\
2003 & 477.540 & 160.000 & 90.000 \\
2004 & 592.850 & 153.320 & 71.000 \\
2005 & 629.630 & 174.920 & 66.010 \\
2006 & 581.380 & 126.170 & 66.000 \\
2007 & 710.150 & 124.780 & 65.270 \\
Média & 459.088 & $\mathbf{1 7 5 . 5 5 9}$ & $\mathbf{1 0 3 . 9 5 1}$ \\
\hline
\end{tabular}

Fonte: Afubra, 2009 (elaborado pelos autores).

O Brasil, de uma posição secundária no mercado internacional do tabaco, assume destaque a partir dos anos de 1990, quando houve expansão nas áreas cultivadas no sul do país, sobretudo no estado do Rio Grande do Sul. As implicações da produção de fumo são profundas, especialmente no meio rural, uma vez que insere regiões em relação direta com as variáveis de mercado, propondo a lógica que consolida a escala local de produção, e articulações com o espaço mundial.

A liderança brasileira articula e amplia relações em que a agricultura familiar está diretamente inserida ao produzir fumo com a introdução de modernas técnicas produtivas, o que permite diminuir os custos de produção e, dessa forma, ganhar competitividade nos mercados internacionais. Por outro lado, países como Estados Unidos da América e Zimbábue veem a queda das suas respectivas participações por problemas que lhes são peculiares.

A qualidade do fumo brasileiro é uma das características que o tornam diferenciado no mundo inteiro. Suas propriedades físico-químicas únicas e uma estruturada cadeia de produção possibilitam enorme capilaridade dos mercados atendidos. Conforme expressa a Fig. 2, o fumo brasileiro possui inserção em vários continentes.

Os países da União Europeia são os que absorvem boa parte do fumo exportado pelo Brasil, todavia mercados do Extremo Oriente, representados em especial por China e Japão, são importantes, principalmente os chineses por seu mercado de consumo.

De modo geral, percebe-se que as exportações de tabaco do Brasil possuem mercados

Geografia Ensino \& Pesquisa, v. 17, n.3 p. 17-33, set./dez. 2013

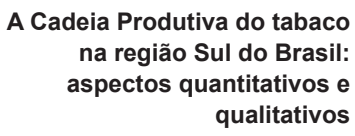

A Cadeia Produtiva do tabaco na região Sul do Brasil: aspectos quantitativos $\mathrm{e}$ qualitativos consolidados e que permitem enormes possibilidades de crescimento. Nesse contexto, não se pode negligenciar a relação que os agricultores têm com o complexo fumageiro é significativa em grande parte dos municípios do Rio Grande do Sul, Santa Catarina e Paraná.

Para fins ilustrativos, a Fig. 3, mostra os municípios no sul do Brasil onde é cultivado o tabaco. A capilaridade da produção fumageira é evidente, uma vez que diversas áreas dos estados do Rio Grande do Sul, Santa Catarina e Paraná possuem áreas destinadas ao cultivo do tabaco.

No sul do Brasil, a cadeia produtiva está organizada e sua vinculação com o mercado 
ocorre no plano internacional.

Figura 2 - Destinos do tabaco brasileiro no exterior - 2011

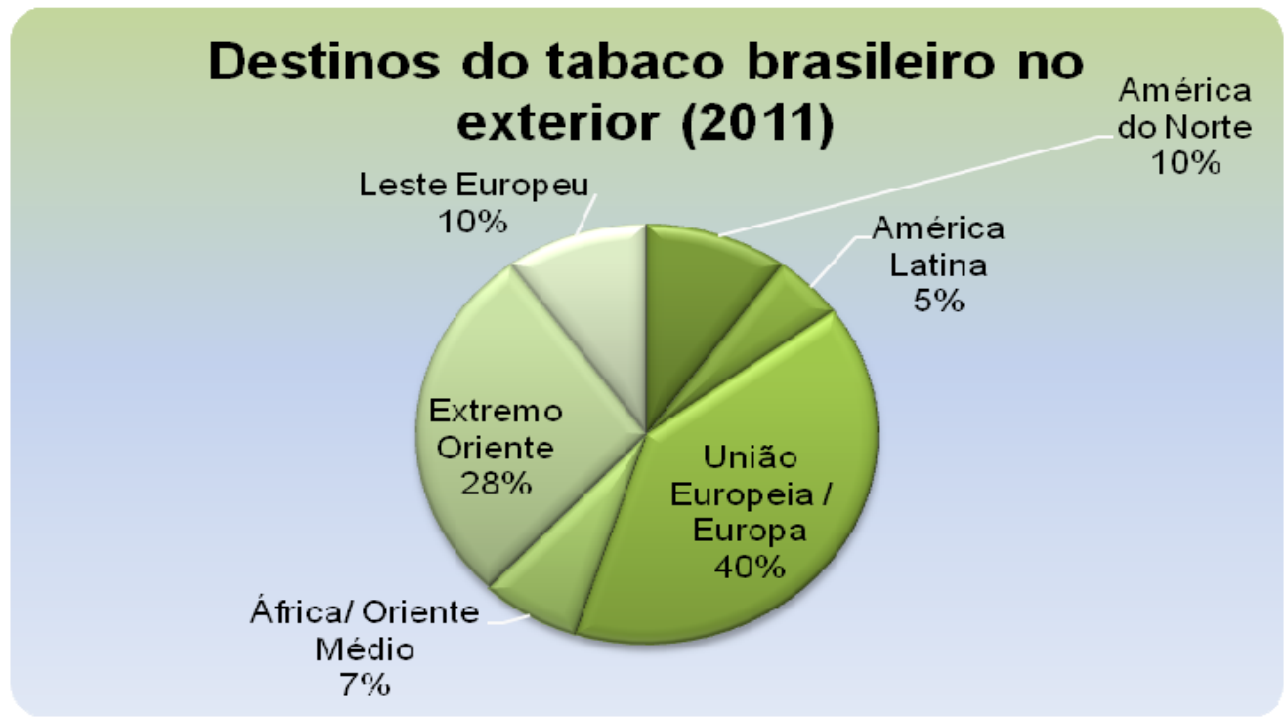

Fonte: SindiTabaco, 2012 (elaborado pelos autores)

Figura 3- Municípios produtores de fumo na Região Sul do Brasil.

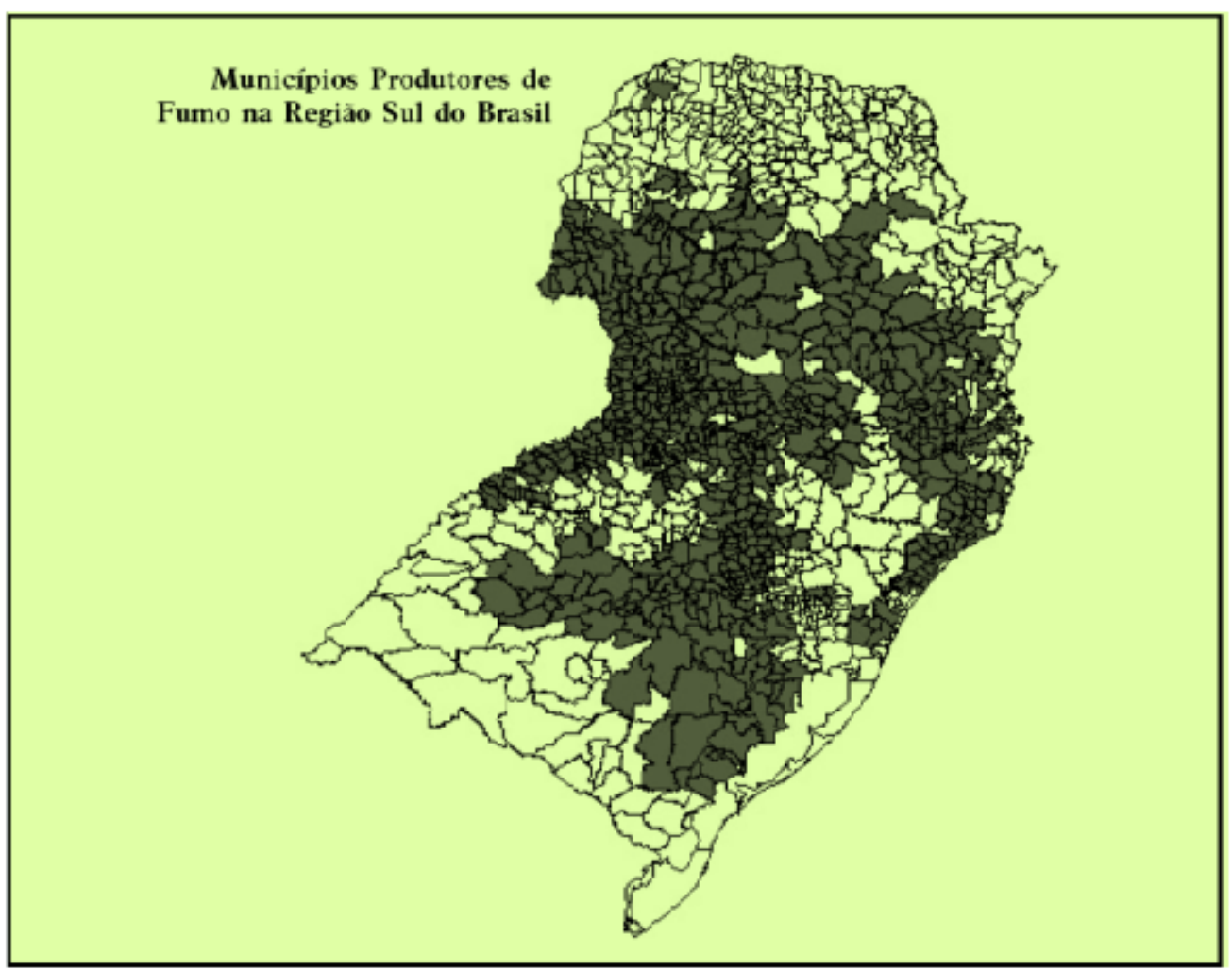

Fonte: Deser, 2005 (adaptado pelos autores).

Geografia Ensino \& Pesquisa, v. 17, n. 3 p. $17-33$, set./dez. 2013

É preciso salientar que a atividade da fumicultura sul-brasileira é operacionalizada por Dutra, E.J.; Hilsinger, R. empresas multinacionais. Raros são os casos de indústrias locais ou empresas de pequeno 
porte na atividade e, quando existem, possuem escala de atuação limitada. O setor fumageiro é dominado por grandes corporações:

As empresas que predominam na fumicultura brasileira, grupos econômicos que estão em constantes processos de fusão e incorporação, são as seguintes: a) Souza Cruz S.A, integrante da British American Tobacco; b)Universal Leaf Tobacco, inc; c) Alliance One International; e d) Kannenberg Barker, Hail \& Cia, integrante da Japan Tobacco International (JTI) S.A. (DUTRA, 2010, p . 75)

Confirmando a tendência, os grupos empresariais passam a predominar em diversas atividades agrícolas, logo é importante destacar as palavras de Abramovay (1998) a respeito da penetração do capitalismo no campo.

A previsão de Marx de que a grande empresa capitalista se generalizaria na agricultura, tanto quanto na indústria, possui ao menos uma virtude histórica: as formas de produção familiar existentes a seu tempo exprimiam sobrevivências de um passado que o desenvolvimento capitalista se encarregaria mais ou menos rapidamente, mas inelutavelmente, de remover . (ABRAMOVAY, 1998, p. 129).

A agricultura familiar adere à lógica de produção capitalista, e amplia sua importância, enquanto setor produtivo responsável pela geração de renda e postos de trabalho. A partir da política de incentivos fiscais, os grupos econômicos fomentam a ampliação da lavoura de fumo através do sistema integrado de produção. Importantes áreas destinadas a cultivos agrícolas (milho, feijão e batata, entre outros) são incorporadas, implantando uma lógica com exigências de produtividade e qualidade com o estabelecimento de metas a serem cumpridas pelos produtores.

É possível destacar que o sistema de integração é uma oportunidade para os grupos empresariais diminuírem os riscos que envolvem a atividade agrícola e por consequência terem suas responsabilidades minoradas.

O sistema de integração constitui uma estratégia implementada pelas grandes indústrias que vem conquistando novos mercados, ampliando sua produção, consequentemente, os lucros. A integração com os agricultores garante produção de qualidade e com baixos custos, pois a empresa não precisa comprar terras, ampliar contratação da mão-de-obra, nem se preocupar com questões trabalhistas (ALVES et al., 2005, p. 145).

Geografia Ensino \& Pesquisa, v. 17, n.3 p. 17-33, set./dez. 2013

A Cadeia Produtiva do tabaco na região Sul do Brasil: aspectos quantitativos e qualitativos
Ainda é importante perceber "que as empresas integradoras representam para muitos o sonhado projeto de desenvolvimento". (ALVES, et.al , 2005, p .154)

Por sua importância econômico-produtiva, as empresas integradoras passam a fazer parte e determinar a gestão das políticas públicas. Em certos casos são as próprias integradoras que direcionam os recursos públicos e orientam os investimentos. A relação estabelecida pelas empresas integradoras é direcionada para atender os interesses de setores específicos, que não necessariamente são aqueles dos agricultores. Diante disso, o agricultor passa a ter a incumbência de ser parte da cadeia produtiva e sua relação na maioria dos casos é submissa.

É necessário enfatizar que a existência da fumicultura não significa que nas propriedades se pratique a monocultura do fumo. Em praticamente todos os casos, nas propriedades onde é desenvolvida, são realizadas outras atividades, embora a fumicultura seja a que traz maior aporte de receita para a propriedade.

O cultivo de tabaco no Brasil tem como base as pequenas propriedades. A Fig. 4 representa a utilização de área nas propriedades familiares. 


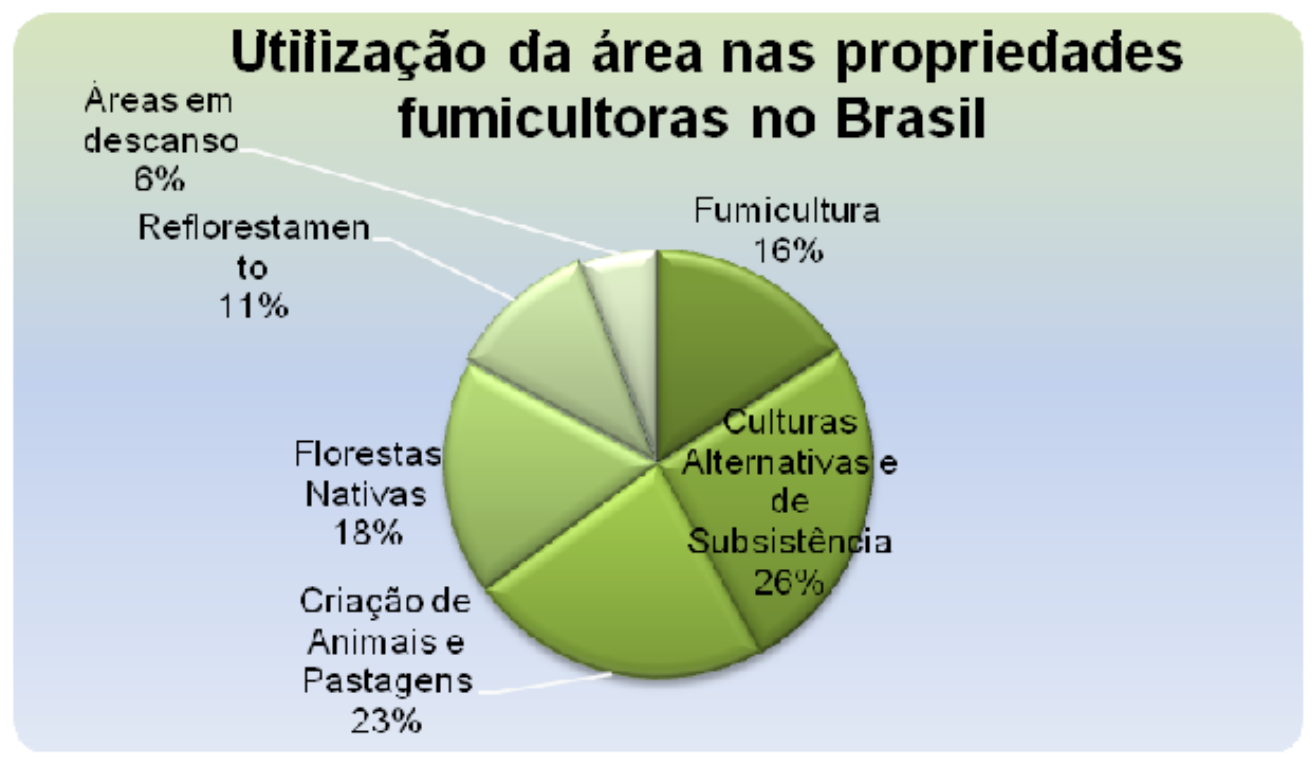

Fonte: SindiTabaco, 2012 (elaborado pelos autores)

Conforme expressam os dados $26 \%$ da área da propriedade são reservados para culturas alternativas e de subsistência, $23 \%$ ficam para criações de animais e pastagens, $16 \%$ é ocupada pela fumicultura, $18 \%$ com florestas nativas, $11 \%$ com reflorestamento e $6 \%$ por áreas em descanso. Mesmo que o fumo ocupe pequenas extensões da área total da propriedade rural e seja responsável por consolidar a renda do grupo familiar, é um assunto polêmico, desde questões que apontam para a dependência dos produtores em relação aos grupos fumageiros, mas pricipalmente que evidenciam as discussões relacionadas à saúde pública.

Nos últimos anos está sendo articulado o tratado internacional que visa regulamentar a atividade, sobretudo o consumo. Esse tratado foi denominado Convenção Quadro ${ }^{2}$ para o controle do consumo do tabaco e congrega interesses de mais de 170 países. A discussão desenvolvida pela Convenção Quadro envolve a academia, os produtores, os sindicatos, a indústria e o sistema de saúde, entre outros atores. Surgem argumentos que defendem a atividade (geração de emprego e renda, atividade adequada para as propriedades familiares) e argumentos que a questionam (malefícios à saúde, trabalho infantil e desmatamento, entre outros).

$\mathrm{Na}$ defesa de interesses, a questão central e que não pode ser negligenciada versa sobre as perspectivas da agricultura familiar no horizonte próximo diante do quadro de incertezas quanto à continuidade da atividade. Entende-se que não é possível o governo brasileiro assumir um compromisso internacional sem avaliar as consequências que essa postura causará a milhares de agricultores familiares instalados, sobretudo no sul do Brasil.

Entretanto é preciso salientar que o argumento econômico não deve ser a única via de entendimento. Os malefícios para a saúde humana, causados pelo consumo do tabaco, representam parte da problemática. Por essa razão a Convenção Quadro de controle do consumo dos produtos oriundos do tabaco consolidou as discussões entre os órgãos de saúde pública (que se concentram nas doenças causadas pelo cigarro bem como o custo de seu tratamento) e a indústria (que tenta persuadir o público ressaltando números de geração de emprego e renda).
2- A Convenção Quadro é definida como um instrumento legal, sob a forma de um tratado internacional, no qual os estados signatários concordam em empreender esforços para circunscrever a epidemia causada pelo tabaco, reconhecida como um problema global com consequências graves para a saúde. (INCA, 2004).
Geografia Ensino \& Pesquisa, v. 17, n.3 p. $17-33$, set./dez. 2013 
A atividade fumageira na região Sul do Brasil encontrou as condições propícias para a expansão e consolidação que passa diretamente pela inserção da agricultura familiar. Todavia, os fatores são múltiplos: é possível identificar a presença do Estado, com a concessão de incentivos fiscais; a estruturada cadeia produtiva e toda a logística necessária para a interconexão de mercados que articula diferentes escalas.

A atividade econômica da fumicultura está em expansão desde a década de 1980. Propiciou a formação de uma cadeia produtiva, conforme demonstra a Fig. 5 que envolve no Brasil cerca de 2,5 milhões de pessoas.

Figura 5- Cadeia produtiva do fumo

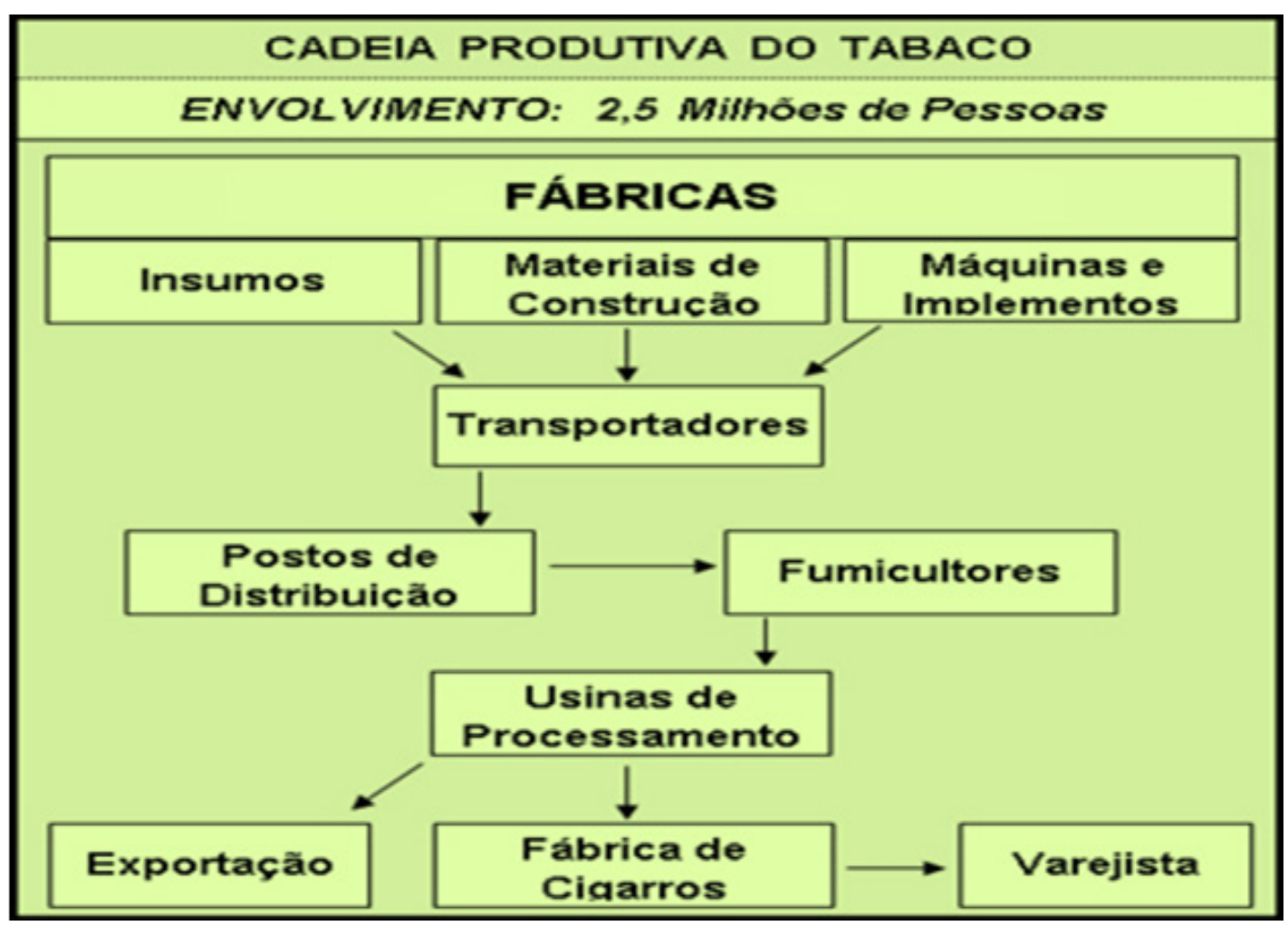

Fonte: Afubra, 2009 (adaptado pelos autores).

Geografia Ensino \& Pesquisa, v. 17, n.3 p. 17-33, set./dez. 2013

\section{A Cadeia Produtiva do tabaco na região Sul do Brasil: aspectos quantitativos $\mathrm{e}$ qualitativos}

Partindo do produtor até o consumidor final (o fumante), há uma ampla gama de serviços intermediários (bancos, serviços técnicos especializados, diaristas etc.) com utilização de expressivo contingente de mão-de-obra. À montante existem as empresas que fornecem os insumos (adubos, sementes, equipamentos, agrotóxicos, entre outros produtos.). A dinâmica abarca vários setores da atividade econômica, gerando empregos no campo e no meio urbano setor secundário (indústrias) e setor terciário com centros de distribuição e o comércio varejista.

A Tabela 2 destaca os dados relativos à produção fumageira na região Sul do Brasil desde as safras 1979/80 até os anos de 2010/2011, explicitando o número de famílias produtoras, hectares plantados e produção total ( $\mathrm{t})$.

Os estados da região Sul do Brasil (Rio Grande do Sul, Santa Catarina e Paraná) possuem importância no contexto nacional, pela produção obtida, envolvendo expressivo número de famílias (esse fato justifica a escala mesoregional), movimentando a economia e assim gerando empregos e renda nos meios urbano e rural. Os valores demonstram a importância que a produção fumageira alcançou principalmente no que se refere ao número de famílias que 
empregam a força de trabalho diretamente na produção. Nas safras 1979/80 estimava-se o número de famílias da ordem de 94.080. Já na safra 2010/11 houve aumento indicando a quantidade de 186.810 famílias produtoras.

Tabela 2 - Evolução da fumicultura na Região Sul do Brasil

\begin{tabular}{lccc}
\hline Safra & $\begin{array}{c}\text { Famílias } \\
\text { Produtoras }\end{array}$ & $\begin{array}{c}\text { Hectares } \\
\text { plantados }\end{array}$ & Produção $(\mathrm{t})$ \\
\hline $1979 / 1980$ & 94.080 & 171.080 & 286.090 \\
\hline $1989 / 1990$ & 127.400 & 201.940 & 367.960 \\
$1999 / 2000$ & 134.850 & 257.660 & 539.040 \\
\hline $2000 / 2001$ & 134.930 & 253.790 & 509.110 \\
\hline $2001 / 2002$ & 153.130 & 304.510 & 635.110 \\
\hline $2002 / 2003$ & 170.830 & 353.810 & 600.540 \\
\hline $2003 / 2004$ & 190.270 & 411.290 & 851.060 \\
\hline $2004 / 2005$ & 198.040 & 439.220 & 842.990 \\
\hline $2005 / 2006$ & 193.310 & 417.420 & 769.660 \\
\hline $2006 / 2007$ & 182.650 & 360.910 & 758.660 \\
\hline $2007 / 2008$ & 180.520 & 348.720 & 713.870 \\
\hline $2009 / 2010$ & 185.160 & 401.703 & 669.619 \\
\hline $2010 / 2011$ & 186.810 & 372.930 & 832.830 \\
\hline Média & 163.999 & 330.383 & 644.349 \\
\hline
\end{tabular}

Fonte: SindiTabaco, 2012 (Organizado pelos autores).

Os estados da região Sul do Brasil (Rio Grande do Sul, Santa Catarina e Paraná) possuem importância no contexto nacional, pela produção obtida, envolvendo expressivo número de famílias (esse fato justifica a escala mesoregional), movimentando a economia e assim gerando empregos e renda nos meios urbano e rural. Os valores demonstram a importância que a produção fumageira alcançou principalmente no que se refere ao número de famílias que empregam a força de trabalho diretamente na produção. Nas safras 1979/80 estimava-se o número de famílias da ordem de 94.080. Já na safra 2010/11 houve aumento indicando a quantidade de 186.810 famílias produtoras.

É possível salientar o aumento na área cultivada, e a produção total alcançada, como, por exemplo, o valor estimado de hectares plantados na safra 1989/90, que era de 201.940, e na safra 2010/11 apresentava 372.910 hectares cultivados, comprovando aumento na área destinada a atividade.

Quando se leva em consideração o contexto em que se dá a produção, basicamente em propriedades familiares, vislumbra-se sua importância com a geração de empregos e renda em áreas rurais.

Como fica evidenciado na Fig. 6, a fumicultura no sul do Brasil utiliza na maioria dos casos mão-de-obra do grupo familiar.

A indústria fumageira consolida com os agricultores familiares a produção por contrato. A origem dessa relação desigual está na operacionalização da integração produtor/indústria

Geografia Ensino \& Pesquisa, v. 17, n. 3 p. $17-33$, set./dez. 2013

Dutra, E.J.; Hilsinger, R. 
mediante a celebração de contratos de fomento, produção e comercialização. Essa característica marca a dependência e a subordinação do agricultor aos interesses da indústria e o caráter de exclusividade que rege essa relação.

Figura 6 - Colheita de fumo no município de Canguçu (RS)

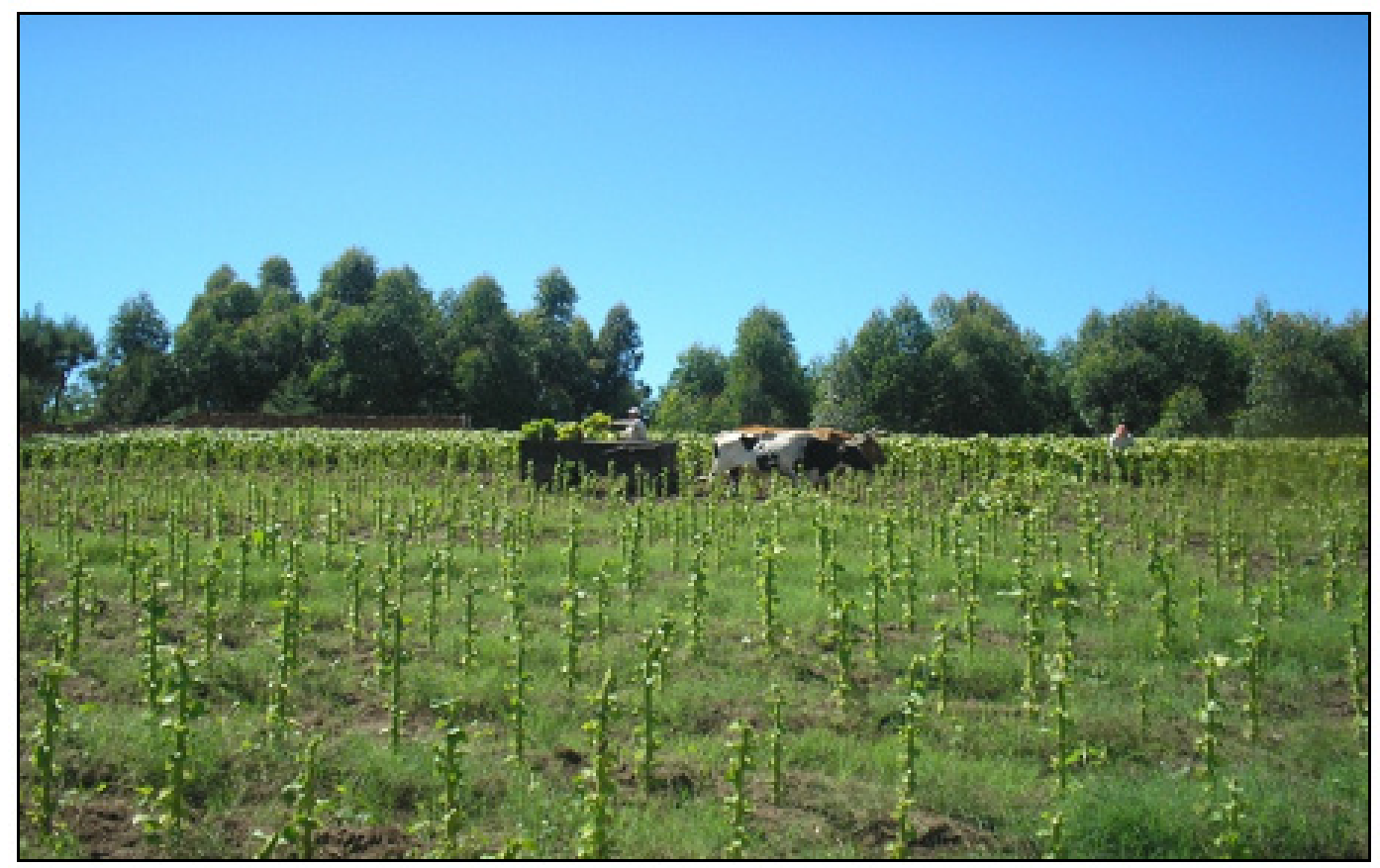

Fonte: acervo dos autores, 2009

A indústria fornece os insumos, investimentos em infraestrutura e assistência técnica. A contrapartida do produtor é a produção nos padrões de qualidade exigidos pela indústria e a exclusividade de comercialização.

É importante evidenciar que:

Em muitos casos os técnicos da empresa passam a ser os administradores da propriedade, pois, além da assistência em relação à produção integrada, sugerem determinados tipos de cultivos que estejam de acordo com as exigências e interesses da empresa. Nesse sentido, o agricultor integrado, além de perder sua autonomia em relação à produção, perde a capacidade de decisão e gestão da propriedade (ALVES et al. 2005, p . 148).

Geografia Ensino \& Pesquisa, v. 17, n.3 p. $17-33$, set./dez. 2013

\section{A Cadeia Produtiva do tabaco} na região Sul do Brasil: aspectos quantitativos e qualitativos

Outro tema complexo são os acordos comerciais entre partes desiguais (indústria/ produtor) onde a indústria tende a ser beneficiada em detrimento do produtor. As principais polêmicas envolvem preço do produto, classificação e comercialização. As consequências dessa relação está nos problemas socioeconômicos como a dependência e a atuação limitada dos produtores frente às empresas fumageiras, representado pelas elevadas dívidas que os produtores contraem no decorrer das safras para poder produzir com a qualidade requisitada pelo mercado.

Os problemas ocasionados pela fumicultura são amplos, de ordem ambiental, destacase a poluição dos cursos de água, em razão das elevadas quantidades de agrotóxicos utilizados. Ainda do ponto de vista ambiental, existem impactos como desmatamento para atender as necessidades das estufas de secagem. Em razão disso, tem sido política constante a implantação de matas exóticas como eucalipto e acácia para atender a demanda existente. O impacto da 
implantação dessas matas exóticas, ainda é uma incógnita, em razão da falta de um zoneamento em grande parte das propriedades que indique as áreas adequadas para esse tipo utilização.

Outro dos inconvenientes está vinculado diretamente, à intoxicação dos agricultores que manipulam os agrotóxicos utilizados na produção, com vários casos de envenenamento por práticas inadequadas na aplicação. Embora as indústrias do setor ofertem palestras e informações sobre manuseio correto, ainda persistem muitos problemas em virtude, por exemplo, das dificuldades que os agricultores têm em compreender a linguagem técnica utilizada nas embalagens, ou em algumas situações pontuais por descuido na aplicação.

Dentro do contexto de inconvenientes que envolvem a fumicultura, existe a utilização do trabalho infantil de membros da família, em uma atividade que sabidamente é degradante. Algumas medidas tem sido tomadas, em especial em acordos entre ministério publico e as fumageiras, que tem surtido efeito, diminuindo consideravelmente a incidência dessa problemática relacionada à mão de obra infantil.

Embora o tabaco constitua-se na em uma das mais importantes fontes de renda para parcela da agricultura familiar do sul do Brasil, é histórico o movimento contrário ao setor. Tanto na escala local quanto nacional e internacional, são formuladas políticas restritivas à produção e ao consumo. A Convenção Quadro para o controle do tabaco resultou de negociações entre diversas organizações nacionais e internacionais envolvendo principalmente o tema 'saúde pública'.

O Brasil participou da elaboração do documento citado, tendo sido um dos primeiros países a assinar a versão final. É visível a intenção do governo brasileiro em erradicar a cultura do tabaco, senão imediatamente, no médio e longo prazo, quando as políticas restritivas surtirão seus efeitos. Essas intencionalidades aparecem nas campanhas contra o consumo de cigarros, o banimento da publicidade no rádio e TV, o cerco da legislação sobre o consumo, sobretudo entre a população jovem, sendo indicativos da adoção de medidas rígidas pelo governo brasileiro.

Concomitantemente percebe-se que a cadeia produtiva do tabaco está se tornando seletiva. A indústria privilegia os agricultores adaptados às exigências internacionais de produção e objetiva a produção certificada por organismos internacionais.

A obtenção dessa certificação é utilizada como ferramenta de marketing e publicidade. Embora não queiramos prognosticar situações que não estejam baseadas em fatos, é provável, devido ao ambiente hostil criado, que a produção sofra redução nos próximos anos, fatos que análises posteriores poderão confirmar.

\section{Considerações Finais}

A discussão que envolve a fumicultura é recente, os elementos que possibilitarão entendê-la e explicá-la estão em discussão. São diferentes interesses que envolvem a atividade, sindicato da indústria, prefeituras, entidades de fumicultores que evocam sólidos argumentos na defesa da atividade, especialmente aqueles relacionados aos empregos e impostos gerados.

Já os organismos que repudiam a atividade destacam, por exemplo, os danos à saúde publica e os gastos governamentais em razão do uso do cigarro. Neste contexto, a Convenção Quadro pretende regulamentar e restringir a atividade e possivelmente extingui- lá em território nacional, gerando preocupações aos produtores. É preciso acrescentar que em determinadas regiões do Brasil, em especial do estado do Rio Grande do Sul, a fumicultura é uma das principais atividades econômicas com geração de empregos no meio urbano, mas fundamentalmente no meio rural.

A solução não deve ser simplesmente restringir a cultura agrícola sem medidas de compensação e reconversão produtiva que garantam padrões de rentabilidade semelhantes.

Geografia Ensino \& Pesquisa, v. 17, n.3 p. $17-33$, set./dez. 2013

Dutra, E.J.; Hilsinger, R.

ISSN 2236-4994 
Embora o estudo enfatize os dados econômicos que tendem a ser o argumento pró-fumicultura, os autores estão sensibilizados com os danos à saúde humana e ao meio ambiente causados pela cadeia produtiva do tabaco.

É preciso destacar que a atividade aplica agroquímicos que impactam o ambiente, ainda utiliza madeira no processo de secagem em vários casos com a supressão de matas nativas, fato que tem gerado conflitos com órgãos de fiscalização ambiental.

Os aspectos contraditórios necessitam de uma avaliação detalhada e não estão integralmente contextualizados. Por essa razão não apresenta-se caráter conclusivo e não pretende-se, neste momento, assumir posição favorável ou contrária à atividade econômica, mas realçar os interesses que envolvem a produção de tabaco possibilitando assim a discussão do tema, que não se esgota aqui.

\section{Referências}

ABRAmOVAY, R. Paradigmas do Capitalismo Agrário em Questão. $2^{\mathrm{a}}$ ed. Campinas: Hucitec, 1998.

AFUBRA (Associação dos Fumicultores do Brasil). Disponível em: <http://www.afubra. com.br>. Acesso em: 15 jan. 2012.

ALVES, A. F.; et.al. Espaço e território: Interpretações e Perspectivas do desenvolvimento. Francisco Beltrão; Unioeste, 2005.

BECKER, B. K. O Uso político do território: questões a partir de uma visão do terceiro mundo. In: BECKER, B. K; COSTA, R. H.; SILVEIRA, C. B. (orgs). Abordagens Políticas da espacialidade. Rio de Janeiro: UFRJ, 1986. p.1-8.

CHIZZOTTI, A. Pesquisa em ciências humanas e sociais. $2^{\circ}$ ed. São Paulo: Cortez, 1995.

DELGADO, G. C. Capital financeiro e agricultura no Brasil (1965- 1985). São Paulo: Ícone, 1985.

DESER (Departamento de Estudos Sócio- Econômico Rurais). Disponível em: <http:// www.deser.org.br/>. Vários acessos em: nov. 2011.

DUTRA, E. J. S. O predomínio da fumicultura no Passo dos Oliveiras - Canguçu/RS e as suas consequências. 2010. 127 f. Dissertação (Mestrado em Geografia) - Instituto de Ciências Humanas e da Informação, Universidade Federal do Rio Grande, Rio Grande.

ETGES, V. E. Sujeição e Resistência: Os Camponeses Gaúchos e a Indústria do Fumo. Santa Cruz do Sul: Editora da FISC, 1991.

FIORI, J. L. Globalização econômica e descentralização política: um primeiro balanço.

Geografia Ensino \& Pesquisa, v. 17, n.3 p. 17-33, set./dez. 2013

A Cadeia Produtiva do tabaco na região Sul do Brasil: aspectos quantitativos e qualitativos
Ensaios da FEE, Porto Alegre, v.15, n.2, 1994, p. 295-311.

INCA (Instituto Nacional do Câncer) Disponível em: <http://www.inca.gov.br/> Vários acessos em: nov. 2011.

MARAFON, G. J. Permanências e mudanças no campo: uma leitura sobre as transformações recentes no espaço rural fluminense In: MENDONÇA, F. A.; LÖWEN-SAHR, C. L.; SILVA, M. (orgs). Espaço e tempo: complexidades do desafio e do pensar geográfico. Curitiba: 
Associação de Defesa do Meio Ambiente e Desenvolvimento de Antonina (ADEMADAN), 2009.

RAFFESTIN, C. et.al. Escala e Ação, contribuições para uma interpretação do mecanismo de escala na prática da Geografia. Revista Brasileira de Geografia, v.45, n 1, p.123-135, jan.mar. 1983.

SINDITABACO (Sindicato da Indústria do tabaco). Disponível em: <http://www.sindifumo. com.br>. Vários acessos em: 2012.

\section{Correspondência:}

\section{Éder Jardel Dutra}

E-mail: ej.dutra@bol.com.br

Recebido em 26 de setembro de 2012.

Revisado pelo autor em 28 de dezembro de 2012.

Aceito para publicação em 02 de janeiro de 2013. 